Objective To investigate the causes and burden of work-related COPD in the UK through the use and extension of UK Biobank cohort information on occupational exposure.

Methods UK Biobank is a population-based cohort of over 500,000 people aged between 40-69 years and recruited in 2006-2010. Baseline measurements of spirometric lung function and lifetime smoking history have been collected and are being analysed with information on current employment status translated into standard occupational codes (SOC 2000). An enhanced web-based occupational module based on the hierarchical structure of SOC 2000 will be sent to all participants in 2013 to collect their life-time occupational histories. Subsidiary questions concerning industries, jobs and exposures related to COPD will be included, as well as questions on shift patterns and hours worked. We are developing a general Job Exposure Matrix (JEM) for COPD for application to the Biobank data. The JEM involves allocation of exposure for different airborne pollutant types for each 4 digit SOC code. Results from systematic review and evaluation of the literature on occupational COPD and the currently available disease-specific JEMs are being used to identify key jobs, exposures and occupational burden of COPD.

Results About $40 \%$ of participants have never smoked. At baseline, only $8352(1.67 \%)$ reported that they had been given a diagnosis of chronic bronchitis or emphysema by a doctor. Spirometry data are available for approximately 324000 participants. Preliminary analysis indicates that 30214 men and 25608 women have airflow obstruction (FEV1/FVC <0.7). Of these, $39 \%$ of the women reported never smoking in contrast to about $3 \%$ of the men.

Conclusions This project will provide estimates of the burden of COPD atributable to lifetime occupational exposure in the UK and facilitate the development of a long-term strategy for the prevention of occupational COPD.

\section{CROSS-SECTIONAL STUDY ON RESPIRATORY SYMPTOMS IN WORKERS EXPOSED TO METALWORKING FLUID AEROSOLS}

Brisman, Olin, Andersson, Hammar, Dahlman-Höglund. Sahlgrenska University Hospital \& Academy, Gothenburg, Sweden

\subsection{6/oemed-2013-101717.80}

Objectives To survey which respiratory symptoms are more prevalent in workers exposed to metalworking fluids (MWF) in machine shops compared with referents. Workers with common symptoms from the lower airways will be invited to clinical examinations.

Methods Workers in two large companies answered questionnaires on respiratory symptoms, atopy, working conditions and smoking. Most questions were used in a previous Swedish study of MWF exposed workers (Lillienberg et al, 2010). In each company there were workers exposed to MWF and referents from similar machine shops but not exposed to MWFs. There were 480 MWF exposed workers and 142 non-exposed referents answering the questionnaire. The response rate was $83.6 \%$. $88.7 \%$ of the respondents were male. Prevalence of different symptoms and atopy were compared between exposed and referents by chi-square tests or Fisher's exact test.

Results In general, there were higher prevalences of symptoms in exposed workers. The prevalence of dry cough was $37.7 \%$ in exposed workers vs. $27.5 \%$ in referents $(p=0.0006)$. Prevalence of often occurring self-reported symptoms such as cough, dyspnoea or wheeze when exposed to MWF was $6.2 \%$, and occasional such symptoms was reported by $22.6 \%$ of MWF exposed respondents. There were no significant difference in atopy or never smokers between exposed and referents. Prevalences of current symptoms from eyes, nose and lower airways were higher in exposed workers than in referents and similar as in the previous Swedish study.

Conclusions Metal workers exposed to MWFs reported more respiratory and eye symptoms than blue collar referents from the same companies. In particular, dry cough was significantly more common. MWF exposed workers and referents with dry cough or asthma as well as exposed workers and referents without symptoms will be invited for clinical examinations.

\section{HOW RELIABLE IS A 'YES' AFTER TEN YEARS?}

B E Andersson, Holm, Nilsson, Torén. Sahlgrenska University Hospital, Gothenburg, Sweden

\subsection{6/oemed-2013-101717.81}

Objectives When doing prospective incidence studies of e.g. asthma in the general population using questionnaires, they are often repeated with an interval of five or ten years. We commonly use questions like "Have you ever had asthma?" Reliability usually is studied as test-retest reliability assuming the same conditions. But how reliable is an affirmative response of a question of ever having had a condition after ten years?

Methods In a study of incidence and risk factors of respiratory diseases a random sample of 20000 individuals in a county in Western Sweden born between 1943 and 1973 was sent a questionnaire in 1993. It comprised items about airway symptoms and smoking. 15813 subjects answered (79\%) and at follow-up in 200311463 of them (72\%) answered the questionnaire. The proportion of a yes answer on the second occasion, conditional on having answered yes on the first occasion, with confidence intervals $(95 \% \mathrm{CI})$ was calculated by gender and baseline age groups (20-30 years, 31-40 years, $41-50$ years).

Results The proportion reporting physician-diagnosed asthma 2003 when doing so 1993 was $84.1 \%$ (418/497, 95\% CI 80.687.2). Corresponding figures for reporting "ever had asthma" was $84.2 \%(534 / 634,95 \%$ CI 81.2-87.0), "ever had wheeze since the age of 15 " was $55.3 \%(1109 / 2005$, 95\% CI $53.1-$ 57.5), ever smoking was $93.9 \%$ (5161/5496, 95\% CI 93.294.5). The proportion reporting physician-diagnosed asthma by gender: women $85.7 \%$ (95\% CI 81.1-89.6) and men $82.0 \%$ (95\% CI 76.2-86.9).

Conclusion In this general population study the proportion of an affirmative response of a question of ever having had a condition after ten years, conditional on having answered yes on the first occasion, differed depending of question but not due to gender or age. Ever smoking and asthma were highly reliable in this aspect. There was no difference between reported asthma and physician-diagnosed asthma.

\section{HIGH RESOLUTION COMPUTED TOMOGRAPHY OF THE LUNGS OF ASPHALT WORKERS}

${ }^{1} \mathrm{G}$ Randem, 'Aaløkken, ${ }^{2}$ Ulvestad. 'Oslo University Hospital, Oslo, Norway; ${ }^{2}$ Statens Arbeidsmiljøinstitutt, Oslo, Norway

10.1136/oemed-2013-101717.82 
Asphalt paving workers are exposed to ultrafine particles originating mainly from asphalt paving activities (asphalt fumes) and traffic exhaust. Studies hav ereported asphalt paving workers have more respiratory symptoms, airflow limitation and signs of airway inflammation than other heavy construction workers, and the mortality from respiratory diseases may be higher.

Objectives High resolution computed tomography (HRCT) is useful in assessing the presence of parenchymal abnormalities in the lung. The aim of this study was to explore the distribution of different HRCT findings in a group of asphalt paving workers previously examined with lung function tests.

Methods All the asphalt pavers previously examined with lung function tests in $2005(\mathrm{n}=76)$ were invited to do HRCT of their lungs. They were contacted by telephone and then received a formal request in writing. Of the group, 53 workers accepted doing the HRCT and being part of the study.

Thin-section CT images were obtained in the supine position during breath-holding and deep inspiration at $120-140 \mathrm{kV}$, with 1 or $1.25-\mathrm{mm}$ section thickness at $10-\mathrm{mm}$ intervals.

The images were reviewed separately and in random order by two chest radiologists (with 18 and 12 years of experience, respectively). The observers were blinded to clinical information and histological diagnosis.

Results The distribution of radiographic abnormalities in the CT scans of lungs of asphalt workers was comparable to the distribution in the normal population of the same age.

Results The study group was fairly small. We could not detect radiographic abnormalities of the lung associated with asphalt work.

\section{Session: K. Musculoskeletal disease}

\section{INTERNATIONAL VARIATION IN MUSCULOSKELETAL SICKNESS ABSENCE: FINDINGS FROM THE CUPID STUDY}

${ }^{1} \mathrm{D}$ Coggon, ${ }^{2} \mathrm{~S}$ Vargas-Prada, ${ }^{1} \mathrm{G}$ Ntani, ${ }^{1} \mathrm{~K}$ T Palmer. 'University of Southampton, Southampton, United Kingdom; ${ }^{2}$ Center for Research in Occupational Health (CiSAL), Universitat Pompeu Fabra, Barcelona, Spain

\subsection{6/oemed-2013-101717.83}

Objectives To quantify the variation in rates of absence for musculoskeletal pain across 47 occupational groups (mostly nurses and office workers) from 18 countries, and to explore personal and group-level risk factors that might explain observed differences.

Methods A standardised questionnaire was used to obtain information about musculoskeletal pain, sickness absence and possible risk factors from 12,416 workers (92 to 1017 per occupational group). In addition, group-level data on socioeconomic variables such as sick pay and unemployment rates were assembled by members of the study team in each country. Associations of sickness absence with risk factors were examined by Poisson regression.

Results Overall, there were more than 30-fold differences between occupational groups in the 12-month prevalence of prolonged musculoskeletal sickness absence, and even among office workers carrying out similar occupational tasks, the variation was more than ten-fold. Individual-level risk factors included older age, lower educational level, tendency to somatise, physical loading at work and prolonged absence for non-musculoskeletal illness. However, these explained little of the variation between occupational groups. After adjustment for individual characteristics, prolonged musculoskeletal absence was more frequent in groups with greater time pressure at work, lower job control, and more adverse beliefs about the work-relatedness of musculoskeletal disorders.

Conclusions Musculoskeletal sickness absence might be reduced by eliminating excessive time pressures in work, maximising employees' responsibility and control, and providing flexibility of duties for those with disabling symptoms. Care should be taken not to overstate work as a cause of musculoskeletal injury.

\section{RISK FACTORS OF ACUTE AND SUBACUTE LOW BACK PAIN IN A COHORT OF FRENCH LOIRE VALLEY REGION'S WORKERS}

${ }^{1} \mathrm{~A}$ P Petit, ${ }^{2} \mathrm{Ha}$, 'Bodin, ${ }^{1}$ Le Marec, ${ }^{1}$ Ramond, ${ }^{1}$ Roquelaure. ${ }^{1}$ University of Angers, Angers Cedex 9, France; ${ }^{2}$ Institute for Public Health, Saint Maurice, France

\subsection{6/oemed-2013-101717.84}

Objectives In recent years, emphasis was placed on the determinants of chronic low back pain (LBP) in a tertiary prevention perspective. However, prevention of acute and subacute LBP should remain a goal of primary prevention in the workplace. The objective of this study was to investigate the risk factors for common acute and subacute LBP related to the individual characteristics or occupational exposure factors in a large sample of workers.

Methods This longitudinal study assessed the main biomechanical, psychological and organisational risk factors for LBP, by self-administered questionnaire, between 2002 and 2005, among a sample of 3,710 workers. A total of 2,332 of them were followed-up between 2007 and 2009 for the occupational becoming, health and working conditions. The risk modelling of different durations of LBP was performed using a multinomial logit model with a variable response into four categories: no LBP, short acute LBP $(<8$ days during the preceding 12 months), prolonged acute LBP (8 to 30 days during the preceding 12 months) and subacute LBP ( $>30$ days during the preceding 12 months, but not daily). Individuals reporting chronic LBP were excluded. In addition, analyses were stratified by gender.

Results The prevalence of LBP was $52.4 \%$ among men and $51.2 \%$ among women and decreased according to the duration of LBP regardless of gender $(24.8 \%$ of short acute LBP and $11.6 \%$ of subacute LBP). The combination of a high perceived physical exertion with frequent bending of the trunk was a risk factor for LBP for both genders. In addition, whole-body vibration and low social support were risk factors in men and high tall in women.

Conclusions The impact of biomechanical factors seems to be more important than organisational and psychosocial factors. analyses failed to identify risk factors specifically related to the duration of LBP.

\section{WHAT EXPECTATIONS OF PERSISTENT OR RECURRENT PROBLEMS ARE HELD AMONG PEOPLE WITH MUSCULOSKELETAL SYMPTOMS AND WHAT INFLUENCES THESE EXPECTATIONS?}

H J Harcombe, Herbison, Derrett, McBride. University of Otago, Dunedin, New Zealand

\subsection{6/oemed-2013-101717.85}

Objectives To: 1) investigate expectations about future problems related to musculoskeletal pain among a cohort of workers; 2) to investigate the association between expectations at baseline 